\title{
METAFICCIÓN Y ESCRITURA DEL Desastre en Simone, de Eduardo LALO*
}

Fecha de recepción: 11 de octubre de 2013

Fecha de aprobación: 2 de diciembre de 2013

\section{Resumen}

Este artículo analiza Simone (2011), de Eduardo Lalo, Premio Internacional de Novela Rómulo Gallegos 2013. El texto ficcional presenta la visión desencantada de un escritor puertorriqueño en torno a las posibilidades de la literatura en el siglo XXI. Tiene una narración fragmentada en la que la aguda intertextualidad se funde con imágenes de la ciudad de San Juan, múltiples recuerdos y digresiones sobre la lectura y la creación literaria. Para el estudio de Simone se utilizan conceptos de Maurice Blanchot en La escritura del desastre.

Palabras clave: novela, Puerto Rico, metaficción, desencanto, desastre.

* Artículo de reflexión, resultado de investigación en el proyecto sobre la literatura Latinoamericana desarrollado por el autor en la Universidad del Tolima, entidad que financia el proyecto.

Citar: Gaitán Bayona, J. (Enero - Junio de 2014). Metaficción y Escritura del Desastre en Simone, de Eduardo Lalo . La Palabra (24), 79 - 87
Jorge Ladino Gaitán Bayona Universidad del Tolima, Colombia jlgaitan@ut.edu.co

Doctor en Literatura de la Pontificia Universidad Católica de Chile. Licenciado en Lenguas Modernas de la Universidad del Tolima. Profesor de la Universidad del Tolima. Autor de los libros de poemas Manicomio Rock (2009), Buzón de naufragios (2012) y Baladas para el ausente (2013). Coautor de: La novela del Tolima 1905-2005, bibliografía y reseñas (2008); Cien años de novela en el Tolima 1905-2005 (2011); y Cuentos del Tolima, antología crítica (2011). 


\title{
Metafiction and Writing of Disaster in Simone BY EDUARDo LaLo
}

\begin{abstract}
This article analyzes Simone (2011), by Eduardo Lalo, Romulo Gallegos Internacional Novel Prize 2013. This fictional work presents the vision of a Puerto Rican writer disenchanted with the possibilities of literature in the XXI century. It consists of a fragmented narrative in which intertextuality alternates with images of the city of San Juan, multiple memories, and digressions about reading and literary creation. For the study of Simone we have used the concepts of Maurice Blanchot in The Writing of the Disaster.
\end{abstract}

Key words: Novel, Puerto Rico, metafiction, disenchantment, disaster.

\section{Métafiction et Écriture du Désastre Dans SimONE, D'EDUARDo LALO}

\section{Résume}

Cet article analyse Simone (2011), d'Eduardo Lalo, Prix International de Roman Rómulo Gallegos 2013. Le texte fictionnel présente la vision désenchantée d'un écrivain portoricain autour des possibilités de la littérature dans le XXIème siècle. Il s'agit d'une narration fragmentée dans laquelle l'aiguë intertextualité se fond avec des images de la ville de San Juan, de multiples souvenirs et des digressions sur la lecture et la création littéraire. Pour l'étude de Simone, on utilise des concepts de Maurice Blanchot dans L'écriture du désastre.

Mots clés: Roman, Porto Rico, métafiction, désenchantement, désastre. 


\section{Preliminar}

Hay novelas donde la ciudad es el espejo de quien ha sumado ruinas y solo queda caminar de un lado a otro para ahogar el tiempo, deambular por cafés y calles en las cuales "la decepción es siempre insuficiente" (Blanchot, 1990, p. 11). ¿Y si el personaje de la ficción es un escritor que descree de las posibilidades curativas de la belleza, la sublimación y la catarsis? "El desastre recurre al desastre para que la idea de salvación, de redención, no se afirme aún, produciendo derrelicción, manteniendo el miedo" (p. 19).

En ocasiones, las ficciones que abordan los elementos antes enunciados procuran que la forma sea afín al tema: narración por fragmentos, como pedazos de cristal que hieren y desacomodan al lector. $\mathrm{La}$ escritura del desastre -el título de uno de los libros más destacados de Maurice Blanchot- se presenta en Simone, novela de carácter metaficcional, ganadora del Premio Internacional Rómulo Gallegos 2013, cuyo jurado estuvo integrado por el argentino Ricardo Piglia, el venezolano Luis Duno y el puertorriqueño Juan Duchesne.

Simone fue publicada originalmente en el 2011 por una editorial independiente argentina (Corregidor). Su autor es Eduardo Alfredo Rodríguez Rodríguez (1960), quien firma sus libros y obras de arte plástico como Eduardo Lalo. Se desempeña como profesor en la Universidad de Puerto Rico. Es escritor, fotógrafo y realizador de mediometrajes (La ciudad perdida y Donde). En el 2006 recibió en ValenciaEspaña el Premio de Ensayo Juan Gil Albert. Aunque se reconoce como puertorriqueño, sus documentos legales le han generado inconvenientes al cruzar fronteras, tal como lo advierte en el discurso de recepción del Premio Rómulo Gallegos 2013:

En ese pasaporte concedido a Eduardo Alfredo Rodríguez Rodríguez se le informaba a los aduaneros del mundo que el que tenían ante sí era un ciudadano estadounidense nacido en Cuba y (en esa época, hace unos 30 años, y he aquí otra instancia por la que ha aumentado nuestra invisibilidad) que este documento había sido emitido por el Departamento de Estado del Estado Libre Asociado de Puerto Rico. En lugar del pretendido efecto clarificador del pasaporte, entregaba un documento opaco y turbio. Desde entonces, he debido sintetizar en las fronteras en las que he sido detenido una formulación factual que resulta para muchos casi incomprensible: "No soy estadounidense, no soy cubano, soy puertorriqueño". La explicación larga de esto, la abarcadora pero siempre incompleta, se halla de maneras no del todo evidentes, en mis libros (Lalo, 2013, p. 1).
Si bien buena parte de su periplo y obsesiones temáticas se sitúan en Puerto Rico y San Juan (la ciudad capital), Eduardo Lalo lleva sobre sí la angustia de ser parte de un territorio cuya autonomía es una agónica impostura. Puerto Rico (cuyo nombre oficial es Estado Libre Asociado de Puerto Rico) es una isla con constitución política pero sin soberanía: no tiene presidente sino un gobernador elegido por el mandatario de los Estados Unidos; las decisiones internas pueden ser revocadas por el Congreso estadounidense; Puerto Rico es un estado adicional de la potencia norteamericana y los nacidos en la isla tienen ciudadanía y pasaporte estadounidense pero no participan en votaciones para seleccionar al máximo jerarca de la Casa Blanca, salvo que se encuentren dentro de las fronteras del "Sueño Americano".

Quizás por esa condición trágica de sentirse una suerte de paria cuyo pasaporte da cuenta de la tensión entre el lugar y no lugar, solo restaba a Eduardo Lalo aceptarse como puertorriqueño desde las coordenadas propuestas por la ficción. Esa preocupación por dibujar los contornos de la isla y la geografía física y espiritual de San Juan es una recurrencia aceptada por el escritor al hacer el balance de su obra. Esta se compone de múltiples creaciones de arte plástico 
y de los siguientes libros: El deseo del lápiz (2010), Los países invisibles (2008), Donde (2005), La inutilidad (2004), Los pies de San Juan (2002) y La isla silente (2002). Este último recoge tres libros publicados en las décadas del ochenta y del noventa: En el Burger King de la calle San Francisco (1986), Libros de textos (1992) y Ciudades e islas (1995).

El Premio Rómulo Gallegos 2013 otorgado a Eduardo Lalo por su novela Simone (2011) tomó por sorpresa al autor. Como indica en varias entrevistas, ha publicado con editoriales independientes $\mathrm{y}$ su nombre es desconocido en el continente. Curiosamente la novela premiada recrea con nitidez los desencuentros de los autores isleños con los escritores profesionales de España y Europa. De ahí que en Simone la metaficción ocupe un papel central: ficción que se piensa a sí misma y tematiza los procesos, angustias e inquietudes que se dan en la creación literaria y la lectura.

El premio es un reconocimiento a la literatura puertorriqueña y del Caribe. Muchas veces la academia y los gremios artísticos manejan unos centros de poder y unas metrópolis específicas cuando piensan en la literatura latinoamericana: Buenos Aires, Santiago de Chile, Bogotá, México, Caracas, Montevideo; no obstante, olvidan que en ella están también las creaciones estéticas del Brasil, de grupos indígenas que poetizan en lenguas aborígenes, de escritores chicanos y del Caribe. Este último cobra nuevamente visibilidad con el otorgamiento del Rómulo Gallegos a un autor de Puerto Rico, en contravía a la poca figuración que se le da a la "isla" en el ámbito político. Acaso Simone pueda funcionar como puerta de entrada para que muchos lectores se motiven a abordar la obra de compatriotas de Eduardo Lalo comprometidos con la búsqueda de la belleza y de la universalidad: Luis Rafael Sánchez, Yolanda Arroyo Pizarro, Giannina Braschi, Juan Duchesne, Maira Santos-Febres, Luis López Nieves, entre otros.

\section{Escritura del desastre y autoconciencia narrativa}

El desastre es "estar separado de la estrella" (Blanchot, 1990, p. 10) y quien gira sus ojos al pasado ve un cúmulo de naufragios. La decepción y un dolor intenso mantienen al sujeto en una "muerte diferida" (p. 124). Sin embargo, el desastre puede convertirse en una "fuerza de escritura" (p. 14) y la palabra, sin descuidar su elaboración estética, emerge con violencia para nombrar los abismos a los cuales pueden llegar el hombre, el arte y la academia. Quien narra o poetiza "en la intensidad del desfallecimiento" (p. 15) tiende, en ocasiones, a desacomodar al lector mediante un texto en el que intervienen fragmentos $\mathrm{y}$ se rompen continuidades.
Escribir por fragmentos es siguiendo la línea de Theodor Adorno en Minima moralia- dar cuenta de que la vida ha sido dañada, rota, volada en mil pedazos.

Una ficción en la que interviene lo fragmentario es, igualmente, una aceptación del papel de la intertextualidad: un texto se teje con otros textos, voces y miradas. Al respecto, resulta oportuno el pensamiento del narrador intradiegético en Simone: "Decía Walter Benjamin que en nuestro tiempo la única obra realmente dotada de sentido - de sentido crítico también- debería ser un collage de citas, fragmentos, ecos de otras obras" (Lalo, 2011, p. 53).

Precisamente "un collage de citas, fragmentos, ecos de otras obras" (p. 53) estructura la novela del narrador puertorriqueño: alusiones literarias y filosóficas; artículos de prensa; conceptos de la crítica literaria; contra carátulas de libros donde abundan comentarios ridículos en los que intervienen los lugares comunes y el incienso mutuo de los escritores; entre otros. Toda esa carga intertextual no es gratuita, obedece a las exigencias del relato y del tipo de protagonista: un novelista y profesor universitario, cuyo mundo inevitable son las discusiones intelectuales, las tertulias, la asistencia a congresos académicos sobre los cuales recae un fuerte cuestionamiento: 
Me invitaron al congreso titulado El derecho al pataleo. Siempre me ha sorprendido el simulado populismo con el que se nombra a muchas actividades intelectuales (...) Hubo de todo, desde la lectura de textos bastante apreciables, a la recitación de otros que se hacían insoportables por el empeño de sus autores en citar sin mesura a una media docena de iluminarias internacionales, cuyas apariciones en los textos se hacían inquietantemente previsibles. Imaginé el estupor de esas figuras en caso de que hallaran, en escritos de investigadores de los cinco continentes, fragmentos de sus obras apuntando los asuntos y las conclusiones más inverosímiles (...) Así pasé el día, soñando con las pausas del café, incrédulo al comprobar que alguien era capaz de hermanar en la misma frase a Deleuze con Mistral, así, sin más, sin preaviso ni nota al pie de página, enlazados por una conjunción que a la vez sumaba y desfiguraba (Lalo, 2011, pp. 54-55).

El narrador intradiegético afila la palabra para irse lanza en ristre contra los eventos académicos en los que no siempre se encuentran análisis lúcidos en las ponencias, sino propuestas forzadas e inverosímiles. En dichas ponencias la incoherencia se encubre con el exceso de citas que ter- minan reconciliando lo irreconciliable. La novela lee con mordacidad la forma cómo, en la actualidad, estos eventos han perdido rigor conceptual y diálogo de saberes porque importa más el efectismo de las cifras (la cantidad de ponentes y asistentes) y el vértigo de recitar rápido para recibir el certificado: "En fin, un día de calvario que habría de consignar bajo la rúbrica 'Asistencia a Congresos' con la esperanza de que sirviera de algo a la hora aciaga en que se renovaban los contratos en la universidad" (Lalo, 2011, p. 56).

El protagonista es ácido contra el entorno académico. Pone al banquillo a docentes universitarios cuyos egos inflados por el uso indiscriminado de modas teóricas les sirve para deslumbrar jóvenes que terminan accediendo a sus caprichos sexuales (es el caso de la profesora Carmen Lindo y su relación con Li Chao, una inmigrante china sin familia $y$ sin recursos económicos). Sin embargo, el narrador, quien habla una y otra vez de cada espacio de su cotidianidad, no se atreve a nombrar las clases o los cursos que orienta. Es como si ese silencio en su historia anunciara el vacío y la pérdida de toda pasión por la docencia. No nombrarse en los detalles del trabajo es su forma de insinuar su inconformidad, el cansancio de lo que es: "el ser exhausto de ser" (Blanchot, 1990, p. 22).

En la suma de fragmentos que sustentan su escritura del desastre, el protagonista funde referencias literarias con retazos de recuerdos, instantáneas de su nomadismo por la ciudad de San Juan y agudos pensamientos acerca del fracaso: "Condenado a las esquinas, a las gavetas, a la inexistencia" (Lalo, 2011, p. 20). En las esquinas de una ciudad por la que va sin rumbo ha vaciado sus horas solitarias. En las gavetas de su residencia y de las librerías reposan sus novelas que pocos leen por más que haya promociones $(3 \times 1)$.Su invisibilidad y fracaso lo llevan a no dar su nombre al lector. Es un yo anónimo al que ya no convencen las utopías y las grandes promesas de la civilización ${ }^{1}$.

Este tipo de personaje, a tono con la época, es testigo y confidente de su deterioro y devaluación ontológica: alguien cuyo rostro e identidad se diluyen entre el ajetreo de la urbe y las dinámicas de la globalización. Ajeno a las posibilidades de familia y los proyectos colectivos porque los tiempos

1 Es necesario tener en cuenta a Nathalie Sarraute en La era del recelo, ensayos sobre la novela: "Está ya lejano aquel tiempo feliz de Eugenia Grandet, cuando el personaje, llegado al colmo de su poder, se entronizaba entre el escritor y el lector, igual que los santos de los cuadros primitivos entre los donantes, y hacía a ambos objeto de sus favores; desde entonces el personaje no ha cesado de perder paulatinamente sus atributos y prerrogativas (...) Todo lo ha perdido, poco a poco, sus antepasados, su casa solariega, sus vestidos, su cuerpo y su rostro y, por encima de todo, ese bien precioso entre los demás: su propio carácter y, a menudo, su propio nombre" (1956, p. 3). 
de hoy exaltan los individualismos para desintegrar grupos y rebeldías. Personaje que "todo lo ha perdido" (Blanchot, 1990 , p. 3), cuya "soledad sin consuelo" (p. 16) ha rebosado la copa y lo obliga a abrirse, a contarlo:

Pensar desde la nada, desde este nada pasa, desde aquí. Y lo digo con la euforia del que ha perdido la esperanza y sigue y pervive. Escribir sin salidas, desde cualquier sitio, en esta ciudad opaca por ejemplo, sabiendo que esta actividad resulta incomprensible para mis vecinos y que, de cualquier manera, estas páginas no llegarán a ellos. Escribir desde un final que no dejará de ser, que acaso no haya sido otra cosa que final (Lalo, 2011, p. 19).

Ese "escribir sin salidas" (Lalo, 2011, p. 19) insinúa que la belleza no siempre es refugio. Las metáforas sobre el arte y sus virtudes curativas para dar tregua al ser mediante la sublimación y la catarsis no todas las veces aplican para autores del presente. Aunque la ficción sea una morada para quien ha perdido incluso la patria idea de Theodor Adorno en Minima moralia- también es factible que "al final el escritor no podrá ya ni habitar en sus escritos" (Adorno, 2006, p. 92). La propia ficción resulta incómoda al escritor y lo obli- gan a reconocer las angustias, temores y abismos que rodean la creación estética. De ahí que la metaficción ${ }^{2}$ ocupe un papel central en Simone.

La metaficción genera una mirada introspectiva a la estructura del relato y las tensiones que se dan durante los procesos de creación y recepción. Dinamita las fronteras de los géneros y los límites entre la ficción y la crítica literaria. Una novela donde se da intensamente la autoconciencia rompe toda camisa de fuerza y se llena de licencias poéticas para detener por momentos la narración de las acciones de los protagonistas y reflexionar acerca de lo que se ha contado, el sentido del lenguaje y de la belleza, las relaciones problemáticas entre historia, texto y contexto. El escritor, cansado de las especulaciones de los teóricos, juega a ser, dentro de su relato, el teórico de su propia creación, delata sus deudas con el canon universal y exhibe - como una suerte de striptease pausado y evocador- su base enciclopédica, las fuentes de su escritura, las lecturas que rodean el acto de (re)creación de la belleza. Por eso en la novela de Eduardo Lalo circulan: conceptos sobre la intertextualidad; opiniones sobre El extranjero de Albert Camus y la obra de Simone Weil; pasajes que se reflexionan de El paroxista indiferente de Jean Baudrillard y de Los demasiados libros de Gabriel Zaid; discusiones sobre las posibilidades e imposibilidades de una literatura puertorriqueña; nociones sobre el papel de la lectura en el siglo XXI. Frente a este último aspecto, el protagonista de Simone indaga el fenómeno a partir de la comprensión del pensamiento de Zaid:

"Los sentimientos de culpa de la gente que escribe son conocidísimos, y en parte explican la obsesión de poner la pluma al servicio de 'causas útiles', para sentirse menos inservibles". Gabriel Zaid, Los demasiados libros.

Leo este libro en una repostería. Cerca de mí, tres cubanos hablan a gritos. El más joven, con un bastón fantasioso descansando entre sus piernas, dice que no vio una vaca hasta los diecisiete años. La conversación me distrae. Zaid trata el acto de leer desde el aprendizaje del deletreo hasta la comprensión de la estructura de todo un libro. "La persona no lee libros porque nunca aprendió a leerlos, porque nunca 'les dio el golpe', porque nunca les encontró el gusto, por lo cual nunca le gustaron". Pienso en estos hombres que hablan con vozarrones que pretender realzar el valor de lo que dicen, en los empleados de

2 Se tiene en cuenta el concepto propuesto por la profesora Patricia Waugh, quien la define como "la escritura ficcional que autoconsciente y sistemáticamente orienta la atención en su carácter de artefacto en orden a cuestionar la relación entre ficción y realidad" (1984, p. 64). Esa autoconciencia narrativa permite que en el texto se dé "una crítica de sus propios métodos de construcción" (p. 64). 
la repostería, en los otros comensales. Soy el único en el local con un libro. A esta hora, ya entrada la mañana, ni siquiera alguien tiene un periódico. Al sentarme y sacar el volumen de la mochila, sentí una ligera y remota vergüenza. Era como hacer el ridículo en el patio de la escuela (Lalo, 2011, p. 31).

La cita -de un alto nivel de visibilidad y precisión en el lenguaje para que el lector se compenetre con la escena narrada-pone en consideración la idea de que quien se sumerge en la lectura es un rara avis en un mundo donde lo efímero y la colección de instantes importan más que las tareas complejas del espíritu, aquellas que se alimentan de la lentitud ritual de una buena novela, en vez del vértigo de una vida líquida en la cual todo pasa tan rápido como agua que se escapa de las manos (tal como lo reflexiona Zygmunt Bauman en varios de sus libros). ¿Qué hacer cuando la tontería rompe en gritos sin ningún sonrojo y hace sentir fuera de lugar a quien se entrega al arte y sus bienes simbólicos? ¿Por qué hasta leer periódicos en una repostería luciría ridículo? Las preguntas sobre las causas útiles e inútiles de la lectura y la escritura cobran sentido cuando la escena configurada por el escritor puertorriqueño tiene un referente crítico desde el cual puede ser contemplada: el protagonista al padecer "una ligera y remota vergüenza" (Lalo, 2011, p. 31) por ser el único lector en un sitio público acaba de estudiar un libro que alude a lo que está viviendo.

El protagonista sin nombre de Simone acepta que difícilmente un novelista puertorriqueño sobreviva con la publicación de libros. Desde su mirada, el autor que se confía demasiado de su talento y no tiene un trabajo distinto a las letras se degrada, a tal punto que termina convertido en un "buscón superviviente de múltiples catástrofes económicas" (Lalo, 2011, p. 60) y sobre él recae la lástima, yendo de un lado a otro para conseguir comida o un proyecto cultural que le otorgue unos mínimos ingresos: "El escritor es un atleta de la derrota" (p. 197). Derrota en la cual late la incomodidad de saber que en ocasiones la propia academia es indolente frente a la literatura nacional, pero lisonjera frente a muchos extranjeros que han traicionado sus convicciones estéticas cuando aceptaron las exigencias del mercado. Resulta cautivante un momento final en la novela donde los profesores universitarios se reúnen para posar ante las cámaras y saturar de elogios a un escritor español que ha llegado "en gira de autógrafos" (p. 194). Los únicos ajenos al clan de halagos son el protagonista y un amigo, García Pardo, quien señala:

Allá en España han perdido el norte. Existe un medio literario que necesita ma- nuscritos, volúmenes para cada una de las temporadas. El novelista no es más que un productor de historias, un profesional del relato. Nada levanta ronchas, porque casi todos los libros hacen lo mismo, procurar que el tiempo se disuelva en las manos del lector. Ese es el empobrecimiento del que hablaba. En este extremo, la literatura tal como nosotros la entendemos, ha muerto o sobrevive casi clandestinamente, alejada cada días más de las mesas de novedades. Aquí, como en otros países en que el mercado literario apenas existe, aún perdura un tipo de escritor que ha ido desapareciendo en las sociedades en que la edición se ha vuelto casi exclusivamente un negocio. La debilidad de la cultura letrada es siempre la manifestación de un tiempo infame: una época bruta e ingenua (Lalo, 2011, pp. 194-195).

La novela de Eduardo Lalo desplaza su mirada crítica dentro y fuera de Puerto Rico: los autores locales que todavía apuestan por la complejidad de los tejidos narrativos permanecen en la miseria y la clandestinidad. En el exterior (el caso citado de España) es frecuente descubrir un tipo de novelista profesional convertido en simple "productor de historias” (Lalo, 2011, p. 194). Este, para tener éxito en el mercado, hace relatos fácilmente digeribles que no ahondan en los problemas fundamentales de la condición humana o en lecturas complejas de sociedades y tiempos específicos; litera- 
tura comercial en la cual "nada levanta ronchas" (p. 194).

Entre los sinsabores de la docencia universitaria, el hastío de escuchar las quejas de los círculos literarios y la propia escritura que no alcanza para borrar la angustia existencial, al protagonista narrador le llega un amor inesperado de poca duración pero largos traumas. Se enamora de Li Chao, una joven mujer cuya vida es también una larga herida: migrante ilegal china, sueldo miserable en un restaurante oriental, violada en su adolescencia por otro asiático, dudas sobre sus preferencias sexuales, miedos, frustraciones, soledades y problemas psicológicos por no encajar en un territorio que la discrimina por su condición socio-cultural.

Li Chao seduce al protagonista mediante textos misteriosos en paredes y notas cortas. Firma sus mensajes con el nombre de Simone, en homenaje a la escritora francesa Simone Weil, cuya obra se cita y comenta en varios momentos de la novela de Eduardo Lalo. La breve tregua con la soledad se rompe cuando ella decide abandonarlo e irse a los Estados Unidos con su amante, la profesora Carmen Lindo. Se suma entonces una nueva decepción, bien dice Blanchot que el desastre "no tiene lo último como límite" (1990, p. 31). La ausencia sumerge al narrador en la melancolía, "el llorar sin lágrimas” (p. 25), el desfallecimiento: "Todas las veces que he sido frágil, que me he derrumbado. Recordarlas para saber verdaderamente lo que es vivir aquí. Aquí soy frágil como en ningún otro sitio. Aquí están mis grietas" (Lalo, 2011, p. 197).

Las grietas del protagonista no están contadas con tonos lastimeros ni descripciones cargadas de componentes emotivos. En el texto narrativo no tienen cabida ni el patetismo, ni el melodrama. En la novela se descubre una estética de la conmoción donde el lector logra aproximarse a la conciencia y piel del protagonista, gracias a las analogías con diversas ficciones, la intensidad de las atmósferas y la maestría narrativa del autor puertorriqueño.

\section{Conclusiones y apuntes finales}

En Simone existe una conexión profunda entre la frustración del protagonista y su "desconcierto nómada" (Blanchot, 1990, p. 11) por calles, cafés y sitios públicos de San Juan, la capital de Puerto Rico. Artista y ciudad se funden en un solo cuerpo y un solo relato: "He pensado a propósito de ciertas calles y aceras que si las suelas de mis zapatos tuvieran pintura quizás para esta época mis pisadas habrían cubierto por completo su superficie (...) Con estos zapatos marcas expreso la ciudad autobiográfica" (Lalo, 2011, p. 76).
Eduardo Lalo sabe que lo local puede interactuar con lo universal, por eso al ubicar su ficción en San Juan no descuida los valores ecuménicos de la novela: la solidez de la arquitectura textual, la aguda exploración de la existencia a través de los personajes y los recursos poéticos; juegos con tiempos, espacios y focalizaciones que dinamizan el relato.

La elección de un narrador intradiegético cuyo nombre no conoce el lector acentúa una visión desesperanzada sobre la vida y el futuro de la literatura ante las dinámicas de la globalización y de los mercados transnacionales que amenazan la complejidad de las ficciones. Dicha visión se sustenta en una escritura del desastre donde se entrecruzan la intertextualidad y las mordaces reflexiones metaficcionales.

Estratégicamente la narración en primera persona se hace más cercana al lector porque "tiene la ventaja de poseer el aspecto de una experiencia vivida" (Sarraute, 1967, p. 56) y lo pone en contacto con un protagonista que recela de sí, se atreve a cuestionar la belleza y la catarsis. Su "estado de ánimo espiritual especialmente enrarecido" (p. 49) lo hace controvertir la idea de la sublimación como un paliativo efectivo porque muchas veces la ficción no es una casa segura. A veces la belleza no alcanza para apaciguar los demonios internos; el exor- 
cismo es momentáneo (catarsis a medias); la escritura es una casa poseída (llena de placeres, pero también de obsesiones y delirios) donde se espantan demonios pero, tarde o temprano, ellos vuelven para que el escritor siga en los abismos de la memoria, en el malestar profundo contra la cultura y, en ocasiones, contra la propia literatura a la que se aferra.

Eduardo Lalo maneja un humor lúcido y corrosivo al contar hábitos, simulaciones e intrigas que se dan en los círculos literarios y las universidades: las discusiones intelectuales y los congresos donde se pierden los focos de análisis sobre las obras por el exceso de citas y teorías forzadas; los balances comparativos entre la literatura local y el mercado internacional; la doble moral de escritores que se alaban entre sí y luego pasan al odio profundo y los comentarios degradantes; el uso del cono- cimiento para atraer jovencitas y satisfacer gustos sexuales. La academia es puesta al paredón en esta novela. El balance de pérdidas y yerros se intensifica con el uso de una narración por fragmentos, como si el tejido ficcional se hilara con espejos rotos, heridas, ruinas; en definitiva una escritura del desastre donde el desencanto es tema y tono de escritura.

\section{Referencias}

Adorno, T. (2006). Minima Moralia. Madrid: Editorial Taurus.

Blanchot, M. (1990). La escritura del desastre. Caracas: Monte Ávila Editores.

Lalo, E. (2013). El hermoso hoy. Letralia, tierra de letras. Recuperado de http://www.letralia. com/286/especial01.htm

Lalo, E. (2011). Simone. Buenos Aires: Editorial Corregidor.

Sarraute, N. (1967). La era del recelo: ensayos sobre la novela. Madrid: Ediciones Guadarrama.

Waugh, P. (1984). Metafiction: The Theory and Practice of Self-Conscious Fiction. New York: Routledge. 